\title{
MIGRAÇÃO LATERAL DO CANAL DO RIO PARAGUAI ENTRE A CIDADE DE CÁCERES E A ESTAÇÃO ECOLÓGICA DA ILHA DE TAIAMÃ - MATO GROSSO
}

\author{
CÉLIA ALVES DE SOUZA ${ }^{1}$ \\ GUSTAVO ROBERTO DOS SANTOS LEANDRO ${ }^{2}$ \\ JUBERTO BABILÔNIA DE SOUSA ${ }^{3}$
}

\section{Introdução}

$\mathrm{O}$ rio Paraguai se constitui num dos rios mais importantes do Brasil, com seus afluentes percorrendo vasta área de planície, podendo ser considerado uma imensa bacia de recepção de águas e sedimentos devido à sua forma de anfiteatro. O rio principal e seus afluentes percorrem grandes extensões em planícies e pantanais mato-grossenses, contribuindo para a manutenção das características locais do pantanal (SOUZA, 2004).

$\mathrm{O}$ estágio evolutivo do corredor fluvial (calha e planície) reflete as mudanças ocorridas nas condições do sistema de rios em várias escalas temporais, associado à evolução geológica e climática da região e aos efeitos da atividade humana, direta e indireta no canal.

A migração lateral nos canais fluviais está intimamente associada às mudanças nos cursos dos rios e ao desenvolvimento da planície de

\footnotetext{
${ }^{1}$ Universidade do Estado de Mato Grosso (UNEMAT). celiaalvesgeo@globo.com

${ }^{2}$ Universidade do Estado de Mato Grosso (UNEMAT). gustavogeociencias@hotmail.com 3 Instituto Federal de Educação, Ciência e Tecnologia de Mato Grosso (IFMT). jubertobabilonia@yahoo.com.br
} 
inundação. A compreensão de seus processos é, portanto, fundamental para o entendimento de feições fluviais (HOOKE, 1979, p. 25).

A hidrodinâmica dos canais meândricos é caracterizada pela contínua escavação da margem côncava e deposição da carga detrítica na margem convexa, com a relação entre o canal e as planícies aluviais adjacentes (LEOPOLD et. al., 1964, p.201).

A erosão marginal desempenha um importante papel na migração lateral. Este tipo de erosão contribui significativamente para o incremento da carga no fundo dos rios e provoca destruição progressiva da área marginal (THORNE, 1978. p.71). Quanto aos estudos realizados sobre a migração lateral do rio Paraguai, destacam-se as pesquisas de Souza e Cunha (2007), Silva et. al. (2007), Justiniano (2010), Silva (2011), Leandro e Souza (2012) e Leandro et. al. (2012).

O fenômeno de migração dos canais fluviais é facilitado e acompanhado de erosão marginal. Os processos de erosão das margens estão entre os elementos mais dinâmicos da paisagem, sendo que o entendimento sobre seu mecanismo de atuação é fundamental para a explicação da evolução dos diversos elementos da dinâmica fluvial. A erosão das margens tem também importância econômica, como a perda de terrenos cultiváveis em áreas agrícolas e a proteção de obras civis, construídas próximo ao canal fluvial, bem como a complementação de estudos de assoreamento em reservatórios (FERNANDEZ, 1990, p. 37).

O objetivo do estudo é verificar a migração lateral do rio Paraguai em dois diferentes compartimentos. Um deles estende-se da cidade de Cáceres até a foz do rio Jauru, enquanto que o outro se inicia na fazenda Santo Antônio das Lendas e termina na ilha de Taiamã.

\section{Materiais e Métodos}

\section{Área de estudo}

O corredor fluvial em estudo localiza-se no alto curso da bacia do rio Paraguai, no trecho fluvial entre a cidade de Cáceres e a Estação Ecológica da Ilha de Taiamã-MT. Encontra-se entre as coordenadas geográficas $16^{\circ}$ $00^{\prime}$ e $17^{\circ} 00^{\prime}$ de latitude Sul, e $57^{\circ} 30^{\prime}$ e $58^{\circ} 00^{\prime}$ de longitude Oeste (ver 
Figura 1), sendo composto pela calha do rio Paraguai e a planície fluvial marginal sujeita à inundação periódica ou permanente. $\mathrm{O}$ canal apresentase meandrante (curvas sinuosas), enquanto na planície encontram-se várias feições fluviais, dentre as quais destacam-se as baías, lagoas, vazantes, braços, furados e diques aluviais. $\mathrm{O}$ corredor fluvial foi segmentado em três compartimentos, baseando em sua morfologia (Figura 1). Os segmentos I e III apresentam morfologia meandrante, e o segmento II, intermediário, apresenta morfologia de canais retilíneos com baixa sinuosidade. Foram escolhidos os segmentos I e III, por apresentarem migração lateral.

O primeiro compartimento $(32,5 \mathrm{~km}$ de extensão) estende-se da cidade de Cáceres à foz do rio Jauru. O padrão do rio é meandrante, apresentando um processo intenso de erosão na margem côncava, deposição na margem convexa e na planície de inundação (ver Figura 2).

O terceiro compartimento $(31 \mathrm{~km}$ de extensão) inicia-se na fazenda Santo Antônio das Lendas e termina na ilha de Taiamã. O canal perde todo o controle estrutural, alterando sua direção norte-sul para oeste-sudeste, tornando-se novamente meandrante, e aumentando a planície de inundação. Neste compartimento o rio Paraguai atinge os terrenos inundáveis do Pantanal ocorrendo bifurcação no canal principal na qual fica do lado leste um braço de rio, que circunda a ilha de Taiamã (ver Figura 3). Os córregos na maioria das vezes não alcançam o canal principal, enquanto alguns pequenos cursos d'água drenam nas áreas sujeitas à inundação, desaguando em baías e lagoas ou espraiando-se na planície - o que contribui para formar a área de Pantanal.

As baías constituem áreas deprimidas, contendo água, delineando formas circulares, semicirculares ou irregulares. As vazantes são pequenos canais que na época de enchente servem de escorredouro entre as baías, e têm caráter de curso fluvial intermitente. Os braços correspondem aos cursos secundários, conectados ao rio principal. Os furados consistem em canais encontrados, geralmente, em rios de planícies. Eles surgem devido ao rompimento do colo do meandro, podendo evoluir para canal principal.

A área de estudo constitui um complexo sistema condicionado pela vasta planície sedimentar com inundações periódicas, topografia plana, cotas variando de 90 a 95 metros, com predomínio de solos hidromórficos de textura fina. A concentração de argila faz com que os solos sejam muito plásticos e muito pegajosos quando estão úmidos, ao passo que, quando 
secos, são extremamente duros propiciando a formação de fendas que os tornam vulneráveis à erosão, provocando, assim, o desmoronamento em blocos. Essas características contribuem para inundações periódicas, mostrando uma drenagem deficiente. A baixa declividade na foz dos tributários do rio Paraguai dificulta o escoamento, aumentando a planície de inundação e contribuindo para a deposição da carga de sedimentos no leito deste rio e na planície marginal.

\section{Procedimentos metodológicos}

Vários estudos sobre as mudanças no canal baseiam-se no método de avaliação espaço-temporal. No Brasil, destaca-se o uso desse método nas pesquisas realizadas por Fernandez (1990), Souza (2004), Rocha (2002) e Morais (2002). Embora este método possibilite avaliar as adaptações do canal, torna-se necessário adaptá-lo a diferentes realidades.

Assim, neste estudo adotou-se o método espaço-temporal para avaliar as mudanças no corredor fluvial. Realizou-se trabalho de campo para observação e checagem das informações. O espaço refere-se ao canal e à planície fluvial entre a cidade de Cáceres e a Estação Ecológica da Ilha de Taiamã. A pesquisa foi realizada em dois compartimentos (I e III), a partir do padrão do rio. O compartimento I, a partir da cidade de Cáceres até a foz do rio Jauru, e o compartimento III, desde a fazenda Santo Antônio das Lendas até a ilha de Taiamã.

Para analisar as variações espaço-temporais no canal em dois períodos de tempo (1975 a 2008) na estiagem, foram utilizadas as cartas topográficas Folhas Cáceres e Descalvado, escala 1:100.000 do ano de 1975, DSG e imagens de satélite LANDSAT na escala 1:100.000, bandas RBG 2, 4 e 5 - obtidas no INPE para o ano de 2008 -, sendo conferidas as informações às observações de campo.

$\mathrm{O}$ estudo ambiental exigiu o tratamento das informações que constituem a base de dados fundamentais em qualquer tipo de análise aplicada. Para tal, a utilização da tecnologia de um Sistema de Informações Geográficas (SIG) possibilitou o cruzamento de todas as informações disponíveis. Para interpretar dados da hidrografia (canal fluvial, lagoas, baías, braços, furados, vazantes e ilhas) e delimitar a planície de inundação, foram utilizados o software ArcGIS. 
A partir da correlação espacial dos dados obtidos, gerados em 1975 e em 2008, foi possível realizar a espacialização, quantificação e tabulação dos esboços gerados, permitindo, assim, analisar e interpretar os elementos que constituem o corredor fluvial nos referidos anos, bem como avaliar a evolução e adaptação do sistema fluvial.

\section{Resultados e Discussão}

As mudanças na calha do rio resultam da própria dinâmica do corredor fluvial, que está relacionada aos índices de precipitação, regime hidrológico, declividade do terreno, litoestrutura local e características do solo. Estes fatores são essenciais para manter o equilíbrio na dinâmica do corredor fluvial, em termos de erosão, transporte e deposição.

Os compartimentos apresentam dois períodos bem definidos em termos de precipitação: chuvas intensas, de outubro a março; e estiagem, de abril a setembro. Nos meses de dezembro e janeiro as máximas diárias ultrapassam $50 \mathrm{~mm}$, situação típica na região, que possui regimes de precipitações tropicais (SOUZA, 2004, p.19).

A drenagem dos compartimentos é constituída pelo rio Paraguai e, dominantemente, por pequenos afluentes. $\mathrm{O}$ rio Paraguai possui uma dinâmica própria em termos de escoamento do fluxo que reflete seu gradiente suave, aproximadamente $5 \mathrm{~cm} / \mathrm{km}$ (DNOS, 1972, p. 62). Parte do volume de água é desviado no período das cheias para a planície de inundação, além de armazenar-se em lagoas e baías.

Nos compartimentos I e III, o canal fluvial possui uma dinâmica intensa caracterizada por erosão acelerada, provocando a ligação direta de algumas baías e braços com o canal principal, que chega a transferir o fluxo do canal principal para o canal secundário. Sua planície é deprimida, com baías e lagoas drenadas principalmente no período de cheias por vazantes e braços, que são separados por terraços e diques marginais com vários níveis de acumulação, antigos e recentes (SOUZA, 2004, p. 87).

\section{Compartimento I}

Notam-se alguns ajustamentos no canal fluvial, tais como: aumento da largura do canal em alguns pontos (ver Tabela 1), relacionado, 
principalmente, à erosão das margens; diminuição da largura do canal vinculada à deposição de sedimentos; e evolução de alguns pontos do colo do meandro que, inicialmente, formam pequenos canais e evoluem em muitos casos para canal principal. A interação entre o nível de flutuação do fluxo (que diminui o antigo canal) e a deposição de sedimentos faz com que aconteça o assoreamento no antigo canal.

A análise temporal realizada no canal fluvial, nos anos de 1975 e 2008, possibilitou diagnosticar algumas mudanças laterais, tais como: recuo das margens, o rompimento do colo do meandro e o aparecimento de novo canal, em alguns trechos do compartimento I. A ação erosiva proporcionou o rompimento e abertura de pequenos canais, conhecidos como furados. No decorrer de 33 anos alguns furados evoluíram e formaram o canal principal.

A adaptação do rio no período entre 1975 e 2008 proporcionou uma alteração na disposição do canal, em alguns pontos. Foram diagnosticados cinco trechos onde houve a abertura de um novo canal, os quais evoluíram para a condição de canal principal (ver Figura 4). A evolução lateral do canal principal está associada ao estrangulamento do colo do meandro e à erosão marginal. Essas duas mudanças podem estar vinculadas à erosão fluvial.

No primeiro trecho a evolução lateral do canal principal está associada ao estrangulamento do colo do meandro, surgindo um novo canal principal. A alteração do canal principal para secundário contribuiu para mudar o posicionamento do leito principal cerca de 2 quilômetros do sentido oeste para o leste, além da redução na extensão do canal de 4,5 para 1,2 $\mathrm{km}$ ao perfil longitudinal (ver Tabela 2).

No segundo trecho ocorreu o entalhamento de um novo canal fluvial, refletindo o potencial erosivo que provocou o rompimento do colo do meandro e propiciou seu estabelecimento como canal principal em 2008. O surgimento do novo canal principal contribuiu para uma redução de 5,8 para $3,3 \mathrm{~km}$ na extensão do canal. $O$ canal principal passou a ser secundário, diminuindo a profundidade média de 2,5 para 1,8 metros, além da formação de várias barras de sedimentos (Tabela 2). O novo leito sofreu ajustamento no sentido leste - oeste. A migração lateral do leito é típica de rios meandrantes e promove nova organização espacial dos ambientes fluviais. 
No terceiro trecho as características do ambiente vinculadas à capacidade de erosão contribuíram para o rompimento do colo do meandro criando um novo canal fluvial que, no decorrer dos anos, estabeleceu-se como canal principal. Estima-se que houve redução do canal de 5,9 para 1,1 quilômetros de extensão, seguida por uma evolução lateral do canal no sentido oeste - leste (Tabela 2).

No quarto trecho as alterações indicam o rompimento do colo do meandro, transformando o canal principal em secundário no decorrer desses 33 anos. Este comportamento possibilitou uma redução de 3,5 para 1,0 quilômetro na extensão do canal, permitindo também o ajustamento do canal no sentido leste para oeste (Tabela 2).

No quinto trecho observa-se o rompimento do colo do meandro, o que contribuiu para o surgimento de um novo canal que evoluiu para canal principal. Estima-se que a extensão do canal foi reduzida de 3,8 para 1,1 $\mathrm{km}$ mediante o processo de ajuste lateral, no sentido leste para oeste (Tabela 2).

\section{Migração lateral}

Estima-se que a migração lateral no compartimento I, no período de 33 anos, variou de 0,10 a 6,0 quilômetros, apresentando instabilidade no canal. A magnitude da migração pode estar relacionada à variabilidade temporal e espacial da vazão, além de outras características ambientais como o tipo de solo, declividade da planície, vegetação e geologia (ver Figura 4).

A erosão intensa e as deposições de sedimentos contribuíram tanto para mudar a extensão do canal quanto para a migração lateral, formando novo realinhamento no canal em alguns pontos, ao longo do perfil longitudinal.

As mudanças progressivas no compartimento I são responsáveis pela diminuição do meandramento do canal (sinuosidade de 2,20 em 1975, decrescendo para 1,9 em 2008), devido ao rompimento do colo do meandro pela erosão lateral ou pela transferência de direção dos bancos de areias, configurando-se, assim, um novo ajustamento espacial do canal. 


\section{Compartimento III}

No compartimento III - correspondente ao Pantanal - quase totalmente alagado ou sujeito à inundação, a maioria dos afluentes deságua na planície de inundação ou em lagoas e baías, restringindo o volume de água e sedimentos que chegam à calha do rio Paraguai. Portanto, o ajustamento lateral do canal advém da descarga líquida e sólida transportada pelo próprio rio.

Ao correlacionar as informações referentes ao período entre 1975 e 2008, verificou-se que a erosão lateral e a nova adaptação do canal ocorreram no sentido sul - norte e nas curvas dos meandros de oeste para leste (ver Figura 5). Ao alcançar a ilha de Taiamã ocorre bifurcação do rio Bracinho e do rio Paraguai, sendo observada uma redução na largura e migração no sentido sul-norte nos dois canais.

Registra-se o rompimento do colo do meandro em dois trechos desse compartimento, o que contribuiu para o surgimento de novos canais que evoluíram para canal principal. Estima-se que a extensão do canal no primeiro trecho reduziu de 5,6 para 2,1 quilômetros e, no segundo trecho, de 4,4 para $2,6 \mathrm{~km}$, mediante o processo de ajuste lateral no sentido oesteleste.

A análise dos dados referentes à extensão do canal fluvial, nos compartimentos I e III, no período de 1975 e 2008, mostrou alterações expressivas na extensão do canal ao longo do perfil longitudinal. No compartimento I a extensão do canal era de $70 \mathrm{~km}$ em 1975, passando para $56,9 \mathrm{~km}$ em 2008, o que demonstra uma redução de $18,71 \%$. No compartimento III a extensão do canal era de $41 \mathrm{~km}$ em 1975, diminuindo para $37,5 \mathrm{~km}$, ou seja, houve uma redução de $8,54 \%$ na extensão do canal fluvial.

Portanto, ressalta-se que o ajustamento espacial do corredor fluvial observado na escala temporal está relacionado diretamente à descarga (liquida e sólida) e à capacidade de transporte de sedimentos. As oscilações nos níveis dos fluxos são propícias à erosão e deposição de sedimentos.

\section{Mudanças espaço-temporais no canal fluvial}


O ajustamento do canal lateral pode estar vinculado à própria dinâmica (erosão, transporte e deposição de sedimentos) e aos condicionantes ambientais (clima, declividade do terreno, geologia, tipo de solo e vegetação) da planície de inundação.

Essas mudanças laterais no canal resultam de: alteração na direção do fluxo; surgimento de novos braços e furados; alargamento do canal, em resposta ao acúmulo de sedimentos no leito, o que diminui a profundidade; progressiva transferência de curva de meandro; e, transferência da vazão do canal principal para canais secundários, os "furados".

As migrações ocorridas no rio principal (compartimentos I e II) e a abertura de um novo canal podem estar relacionadas ao aumento do débito anual ou plurianual, provocando aceleração do processo erosivo e deposição de sedimentos, que contribuem para o ajustamento do canal e transformam alguns trechos do canal principal em secundários. A abertura do novo canal provoca diminuição na descarga do antigo canal, diminuindo sua capacidade e competência de transporte, aumentando a deposição de sedimentos no fundo e nas margens.

Os tipos de mudanças laterais observadas foram agrupados em duas categorias: (a) alterações resultantes da transferência do canal devida ao rompimento do colo do meandro; (b) a migração lateral do canal devido à erosão das margens ou à deposição de sedimentos que formam bancos e diques marginais.

\section{Considerações Finais}

As mudanças no canal durante o período de 33 anos (1975 a 2008) como a diminuição da extensão e o ajustamento lateral, nas feições morfológicas -, nos dois compartimentos, estão associadas às características ambientais (clima, vegetação, tipo de solo, declividade do terreno, geologia e uso da terra no entorno) e à própria dinâmica do corredor fluvial, em termos de oscilação do nível de água. O que favorece a erosão das margens, a diminuição na capacidade de transporte de sedimentos e a deposição de sedimentos na calha e na planície.

A análise temporal constatou mudanças na posição do canal e nova adaptação na planície, além da diminuição na extensão do canal. As alterações espaciais resultam das atividades laterais e do rompimento do 
colo de meandros, associadas aos mecanismos de erosão, transporte e deposição de sedimentos, que contribuíram para diminuição da sinuosidade do canal fluvial.

O estudo mostrou que a instabilidade da calha ultrapassa os limites do leito menor (calha), atingindo o leito maior (calha e planície). Esse comportamento da drenagem relaciona-se a alguns fatores básicos de entrada no sistema, tais como a alimentação do curso d'água pela descarga líquida e de sedimentos.

As mudanças na extensão do canal estão relacionadas à redução de sua sinuosidade, vinculada ao rompimento do colo do meandro. Os resultados são o aparecimento de novos canais, o realinhamento do canal devido à erosão das margens, bem como o processo de deposição que obstrui parte do canal, originando novas baías e diminuindo a extensão do canal.

Considerando que as mudanças expressivas na calha ocorreram no compartimento I, sugere-se que ao propor qualquer tipo de uso direto ou indireto neste trecho, seja considerada a dinâmica fluvial do mesmo.

\section{MIGRAÇÃO LATERAL DO CANAL DO RIO PARAGUAI ENTRE A CIDADE DE CÁCERES E A ESTAÇÃO ECOLÓGICA DA ILHA DE TAIAM ̃ -MATO GROSSO}

Resumo: Visando analisar a migração lateral do canal no corredor fluvial do rio Paraguai no segmento entre Cáceres e a Estação Ecológica da Ilha de Taiamã - Mato Grosso, dividiu-se o corredor fluvial em três compartimentos, em função dos aspectos morfológicos. Sendo escolhidos os segmentos I e III, por apresentar migração lateral. No primeiro compartimento, o rio possui padrão meandrante dinâmica, caracterizada pela erosão acelerada e deposição de sedimentos na calha e na planície de inundação. No terceiro compartimento, o canal perde todo o controle estrutural, mudando sua direção para oeste-sudeste, tornando-se novamente meandrante com o aumento da extensão da planície, atingindo os terrenos inundáveis do Pantanal. A análise espaço-temporal constatou mudanças na posição do canal e nova adaptação na planície, além de diminuição em sua extensão. As alterações espaciais resultaram das atividades laterais e do rompimento do colo de meandros, associados aos processos de erosão, transporte e deposição de sedimentos, que contribuíram para diminuição da 
sinuosidade do canal fluvial. As mudanças laterais no canal resultaram em: alterações na direção do fluxo; surgimento de novos braços e furados; alargamento do canal, em resposta ao acúmulo de sedimentos na calha; progressiva migração lateral e transferência da vazão do canal principal para canais secundários (furados).

Palavras-chave: Rio Paraguai, dinâmica, feições morfológicas, migração lateral.

THE LARERAL MIGRATION OF THE PARAGUAY RIVER CHANNEL BETWEEN THECÁCERES CITY AND THE ECOLOGICAL STATION OF THE TAIAMÃ ISLAND - MATO GROSSO

Abstract: Aiming at the analysis of lateral migration of the Paraguay River channel in the segment between Cáceres city and the Taiamã Island Ecological Station-MT, we divided this fluvial corridor into three compartments based on morphologic aspects. We select segments I and III to show lateral migration. In the first compartment, the river shows a meanders pattern and its dynamics is characterized by an accelerated erosion and sediment depositions in the bed and in the floodplain. In the third compartment, the channel loses all the structural control, as changing its direction to west southeastern and becomes meandered again, while increasing the extension of the floodplain and reaching the wetlands in the Pantanal. The space-time analysis revealed changes in the channel position and a new adaptation in the floodplain, as well as a decrease in its extension. The space alterations resulted from the lateral activities and the rupture of the meander neck associated with the processes of erosion, sediment transport and deposition, which contributed to a decreased sinuosity of the fluvial channel. The lateral migrations in the channel resulted into: changes in the flow direction; appearance of new secondary channel and channel enlargement in response to the accumulation in the load bed; decreased depth; progressive lateral migration; and transfer of the main channel flow to secondary channels.

Keywords: Paraguay River, dynamics, morphologic features, lateral migration

\section{BIBLIOGRAFIA}


DNOS, (Brasil). (1972). Estudos hidrológicos da bacia do Alto Paraguai (Relatório Técnico). Rio de Janeiro, $284 \mathrm{p}$.

FERNANDEZ, O. V. Q. (1990). Mudanças no canal fluvial do rio Paraná e processos de erosão nas margens: região de Porto Rico, PR. 85 f. Dissertação (Mestrado em Geografia) - Instituto de Geociências e Ciências Naturais, Universidade Estadual Paulista. Rio Claro, SP.

HOOKE, J. M. (1979). An analysis of the processes of river bank erosion. Journal of Hydrology, v. 42, p. 39-62.

JUSTINIANO L. A. A. (2010). Dinâmica fluvial do rio Paraguai entre a foz do Sepotuba e a foz do Cabaçal. 72 f. Dissertação (Mestrado em Ciências Ambientais) - Instituto de Ciências Naturais e Tecnológicas, Universidade do Estado de Mato Grosso. Cáceres, MT.

LEANDRO, G. R. S.; SOUZA, C. A. (2012). Pantanal de Cáceres: composição granulométrica dos sedimentos de fundo no rio Paraguai entre a foz do rio Cabaçal e a cidade de Cáceres, Mato Grosso, Brasil. Ambiente \& Água, n. 2, vol. 7. pp. 263-276.

LEANDRO, G. R. S.; SOUZA, C. A.; CHAVES, I. J. F. (2012). Aspectos sedimentares na baía Negra, corredor fluvial do rio Paraguai, Pantanal de Cáceres - Mato Grosso. Caminhos de Geografia, n. 43, vol. 13. pp. 204216.

LEOPOLD, L. B.; WOLMAN, M. G.; MILLER, J. P. (1964). Fluvial process in geomorphology. San Francisco: W. H. Freeman and Company, $201 \mathrm{p}$.

MORAIS, R.P. (2002). Mudanças históricas na morfologia do canal do rio Araguaia no trecho entre a cidade de Barra do Garças (MT) até a Foz do rio Cristalino na Ilha do Bananal no periodo entre as décadas de 60 e 90. Dissertação (Mestrado em Geografia) - Programa de Pós-Graduação em Geografia, Universidade Federal de Goiás, 176 p.

ROCHA, P. C. (2002). Dinâmica dos canais fluviais no sistema Rio Planície Fluvial do Alto Rio Paraná, nas proximidades de Porto Rico-PR. 169 f. Tese (Doutorado em Ecologia de Ambientes Aquáticos Continentais), Universidade Estadual de Maringá. Maringá, PR. 
SILVA, A.; SOUZA, C. A.; ZANI, H.; REZENDE, D. (2007). Avaliação da erosão na margem direita do rio Paraguai a jusante da praia do Julião município de Cáceres - MT. Revista Geográfica Acadêmica, v. 1, n. 1, pp. 5-19.

SILVA, E. S. F. (2011). Dinâmica fluvial do rio Paraguai entre Furado do Touro e Passagem Velha do Pantanal Mato-grossense no município de Cáceres - Mato Grosso.. 79 f. Dissertação (Mestrado em Ciências Ambientais), Universidade do Estado de Mato Grosso. Cáceres, MT.

SOUZA, C. A. (2004). Dinâmica do corredor fluvial do rio Paraguai entre a cidade de Cáceres e a Estação Ecológica da ilha de Taiamã-MT. $173 \mathrm{f}$. Tese (Doutorado em Geografia) - Centro de Ciências Matemáticas e da Natureza, Universidade Federal do Rio de Janeiro. Rio de Janeiro.

SOUZA, C. A.; CUNHA S. B. (2007). Pantanal de Cáceres - MT: dinâmica das margens do rio Paraguai entre a cidade de Cáceres e a Estação Ecológica da ilha de Taiamã. Revista Eletrônica da Associação dos Geógrafos Brasileiros, Três Lagoas, MS, v. 1, n. 5, maio, pp. 18-41.

THORNE, C. R. (1978). Processes of bank erosion in river channels. 447 f. Unpublished Ph.D. thesis-School of Environmental Sciences, University of East Anglia - UEA. Norwich, UK.

Data de submissão: 04/02/2013

Data de aprovação: 23/08/2014 
Figuras e Tabelas
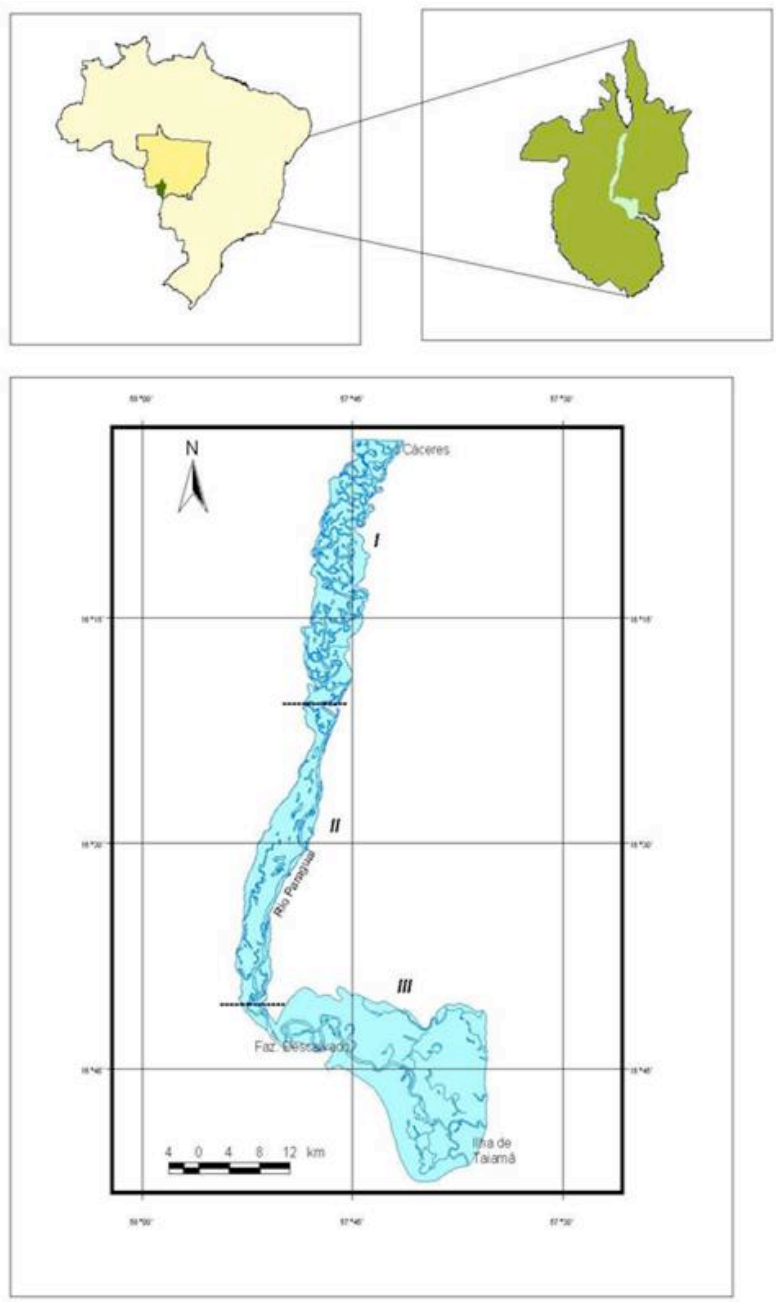
Figura 1: O corredor fluvial do rio Paraguai entre a cidade de Cáceres e a Estação Ecológica da Ilha de Taiamã, sua localização no Brasil e no município de Cáceres. I e III representam os compartimentos estudados.

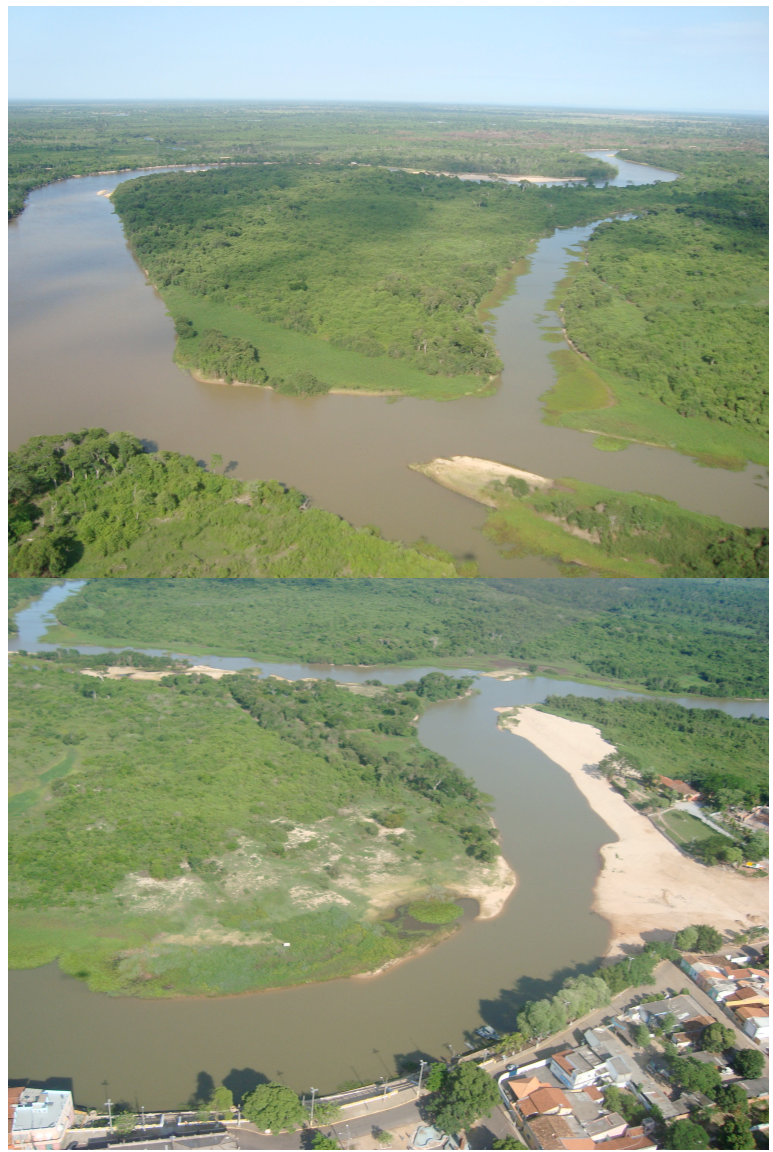

Figura 2: Aspectos relevantes (rio principal, canais secundários, planície de inundação e barras de sedimentos) do rio Paraguai, no compartimento I. 


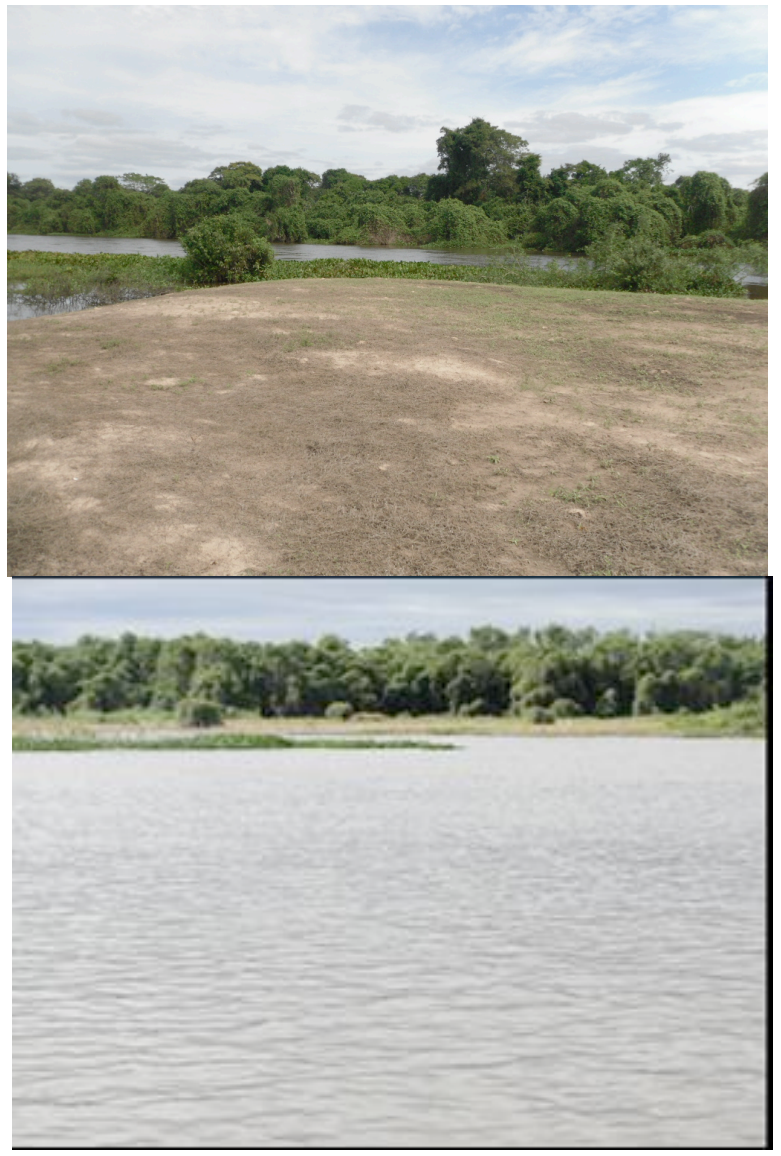

Figura 3: Aspectos relevantes (rio principal, formação de ilhas e barras laterais) do rio Paraguai, no compartimento III. 


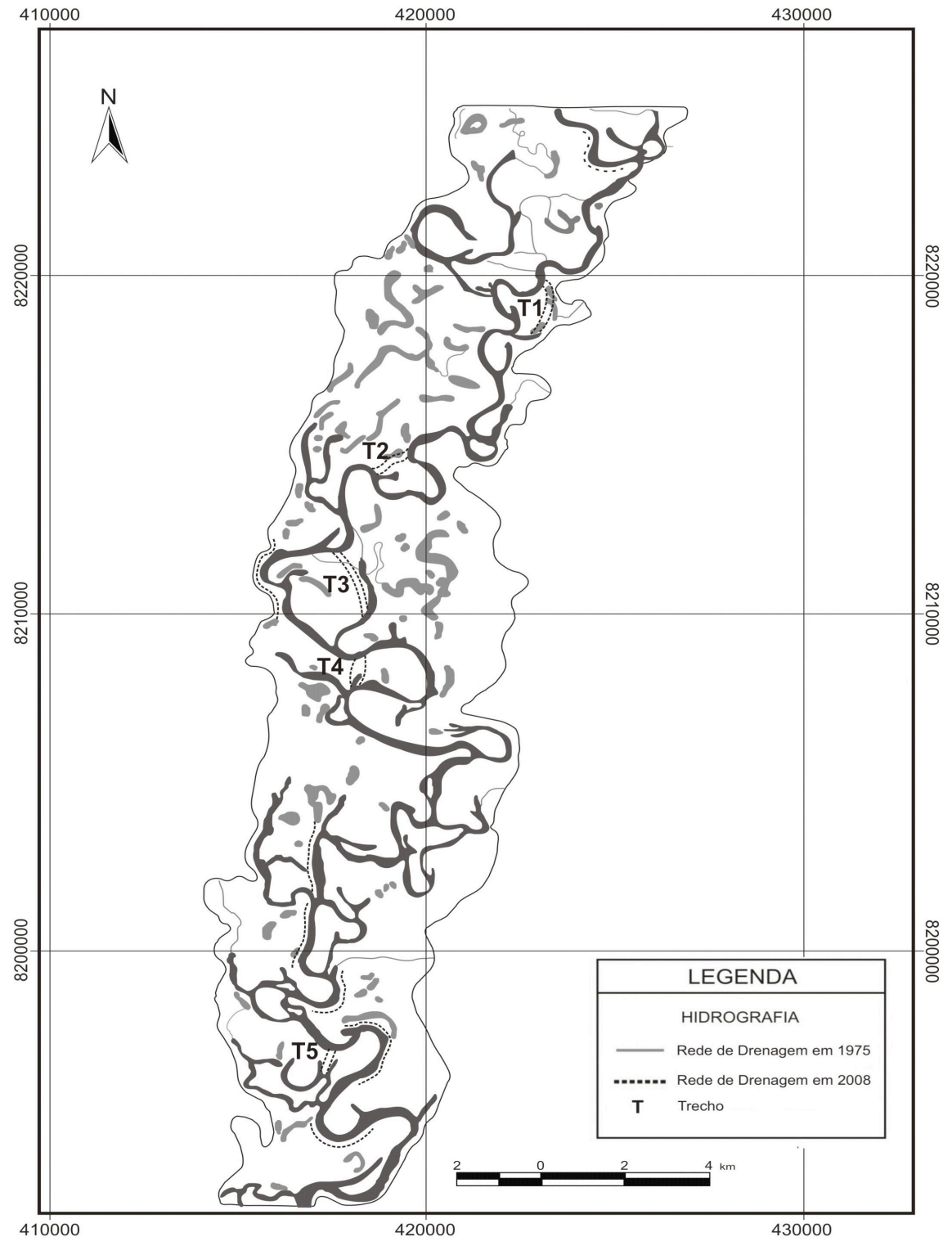


Figura 4: Migração lateral e rompimento do colo do meandro no compartimento I, no período entre 1975 e 2008.

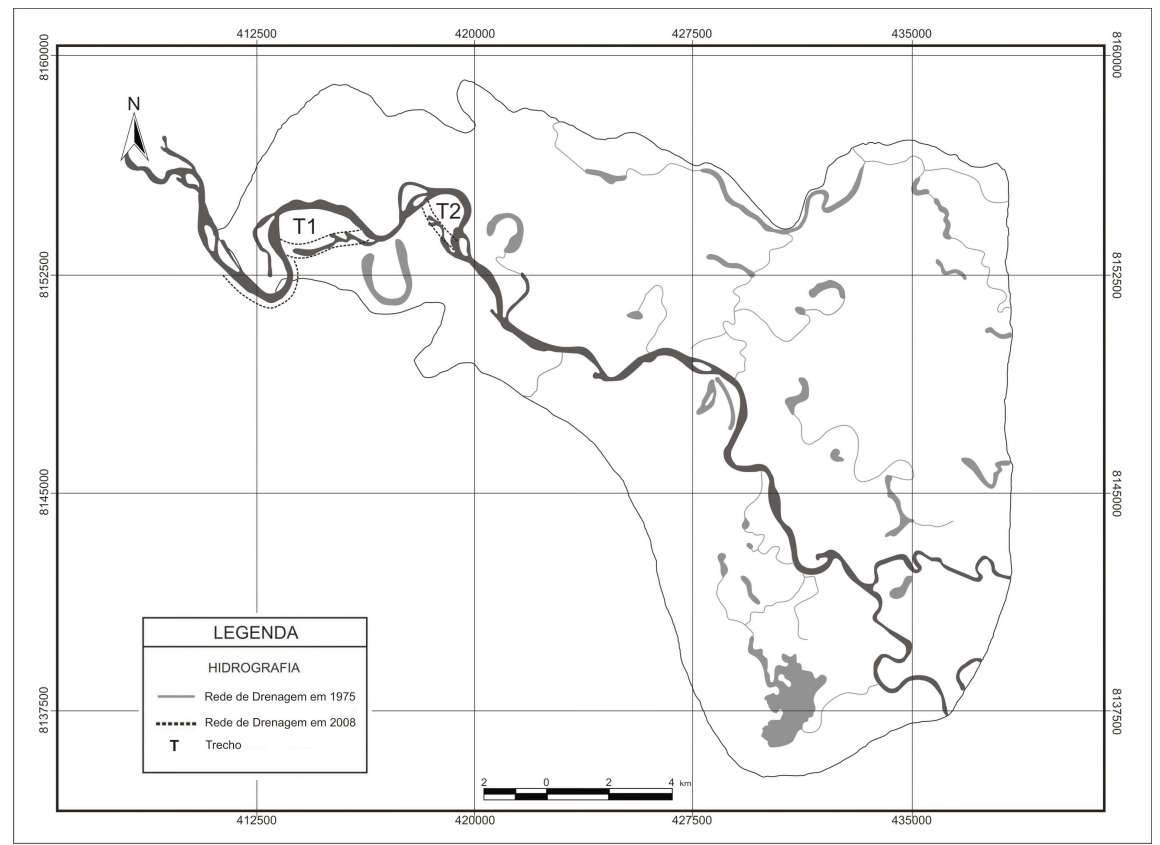

Figura 5: Migração lateral do canal fluvial no compartimento II, entre os anos de 1975 e 2008. 


\begin{tabular}{l|l|l|l|l}
\hline Compartimentos & Trechos & $\begin{array}{c}\text { Canal } \\
\text { principal } \\
1975 \\
\text { Largura (m) }\end{array}$ & $\begin{array}{l}\text { Antigo canal } \\
2008 \\
\text { Largura (m) }\end{array}$ & $\begin{array}{l}\text { Novo Canal } \\
2008 \\
\text { Largura (m) }\end{array}$ \\
\hline I & $1^{\circ}$ & 200 & 149 & 47 \\
\hline I & $2^{\circ}$ & 330 & 283 & 78 \\
\hline I & $3^{\circ}$ & 190 & 146 & 113 \\
\hline I & $4^{\circ}$ & 210 & 243 & 258 \\
\hline I & $5^{\circ}$ & 190 & 78 & 227 \\
\hline III & $1^{\circ}$ & 304 & 306.97 & 111,88 \\
\hline III & $2^{\circ}$ & 202 & 200,21 & 65,60 \\
\hline
\end{tabular}

Tabela 1: Largura do canal em cinco trechos do rio Paraguai no segmento I, nos anos de 1975 e 2008.

\begin{tabular}{cccc}
\hline \multirow{2}{*}{ Compartimentos } & \multirow{2}{*}{ Trecho } & \multicolumn{2}{c}{ Extensão (km) } \\
\cline { 3 - 4 } & & $\mathbf{1 9 7 5}$ & $\mathbf{2 0 0 8}$ \\
\hline I & 1 & 4,5 & 1,2 \\
I & 2 & 5,8 & 3,3 \\
I & 3 & 5,9 & 1,1 \\
I & 4 & 3,5 & 1,0 \\
I & 5 & 3,8 & 1,1 \\
III & 1 & 5,6 & 2,1 \\
III & 2 & 4,4 & 2,6 \\
\hline
\end{tabular}

Tabela 2: Mudanças na extensão do canal nos segmentos cujo colo do meandro encontrase rompido. 